\title{
Macular hole formation following intravitreal injection of ranibizumab for branch retinal vein occlusion: a case report
}

\author{
Daisuke Muramatsu', Ryosuke Mitsuhashi', Takuya Iwasaki ${ }^{1}$, Hiroshi Goto ${ }^{2}$ and Masahiro Miura ${ }^{1 *}$
}

\begin{abstract}
Background: Macular hole formation after anti-vascular endothelial growth factor therapy is a rare complication. We report macular hole formation after intravitreal ranibizumab injection for branch retinal vein occlusion.

Case presentation: A 63-year-old Asian male was treated with intravitreal ranibizumab injection for chronic macular edema with branch retinal vein occlusion in his right eye. Before treatment, best-corrected visual acuity in his right eye was 20/200. Nine days after injection, a full thickness macular hole developed with reduction of macular edema. After pars plana vitrectomy combined with cataract surgery, the macular hole was successfully closed, and the bestcorrected visual acuity in his right eye improved to 20/40.
\end{abstract}

Conclusion: The possibility of an infrequent complication like macular hole should be considered for intravitreal ranibizumab for macular edema with branch retinal vein occlusion.

Keywords: Branch retinal vein occlusion, Macular hole, Ranibizumab, Macular edema, Complication

\section{Background}

Retinal vein occlusion (RVO), including branch retinal vein occlusion (BRVO), is a major retinal vascular disease. Macular edema is the most common cause of visual impairment in eyes with RVO. There are several treatment options for macular edema in RVO, including laser photocoagulation [1], intravitreal steroid treatment [2], and vitrectomy [3]. Recently, various anti-vascular endothelial growth factor (VEGF) therapies including ranibizumab [4] (Lucentis $^{\circledR}$; Genentech, South San Francisco, CA, USA), aflibercept [5] (Eylea ${ }^{\circledR}$; Regeneron, Tarrytown, PA, USA and Bayer HealthCare, Berlin, Germany), and bevacizumab [6] (Avastin ${ }^{\circledR}$; Genentech) are widely used for the treatment of macular edema in RVO. Anti-VEGF therapy has shown favorable results for RVO [4-6], although adverse complications have been reported with this treatment [4]. We report a patient who developed a macular hole $(\mathrm{MH})$ after ranibizumab

\footnotetext{
*Correspondence: mmiuratokyo@gmail.com

${ }^{1}$ Tokyo Medical University, Ibaraki Medical Center, 3-20-1 Chuo,

Ami-machi, Inashiki-gun, Ibaraki 300-0395, Japan

Full list of author information is available at the end of the article
}

injection for chronic BRVO, with closure of this macular hole after vitrectomy.

\section{Case presentation}

A 63-year-old Asian male, diagnosed with BRVO with refractory macular edema, was referred from his home doctor. His vision in his right eye had been slowly decreasing without any treatment for the previous 5 years. The best-corrected visual acuity (BCVA) in his right eye was 20/200 and conventional fundus examination showed retinal hemorrhage followed by chronic BRVO in his right eye. He had a past history of hypertension, but no hyperlipidemia or diabetes mellitus. Optical coherence tomography (OCT) revealed serous retinal detachment and intraretinal edema that was located at the outer retina (Fig. 1a). Central retinal thickness (CRT) from the OCT B-scan image was $542 \mu \mathrm{m}$. Using fluorescein angiography imaging, a small capillary nonperfusion area with collateral vessel formation was detected in the early phase, and dye leakage in the area of the vein occlusion was detected in the late phase (Fig. 1c, d). Slit lamp biomicroscopy revealed that the posterior vitreous 


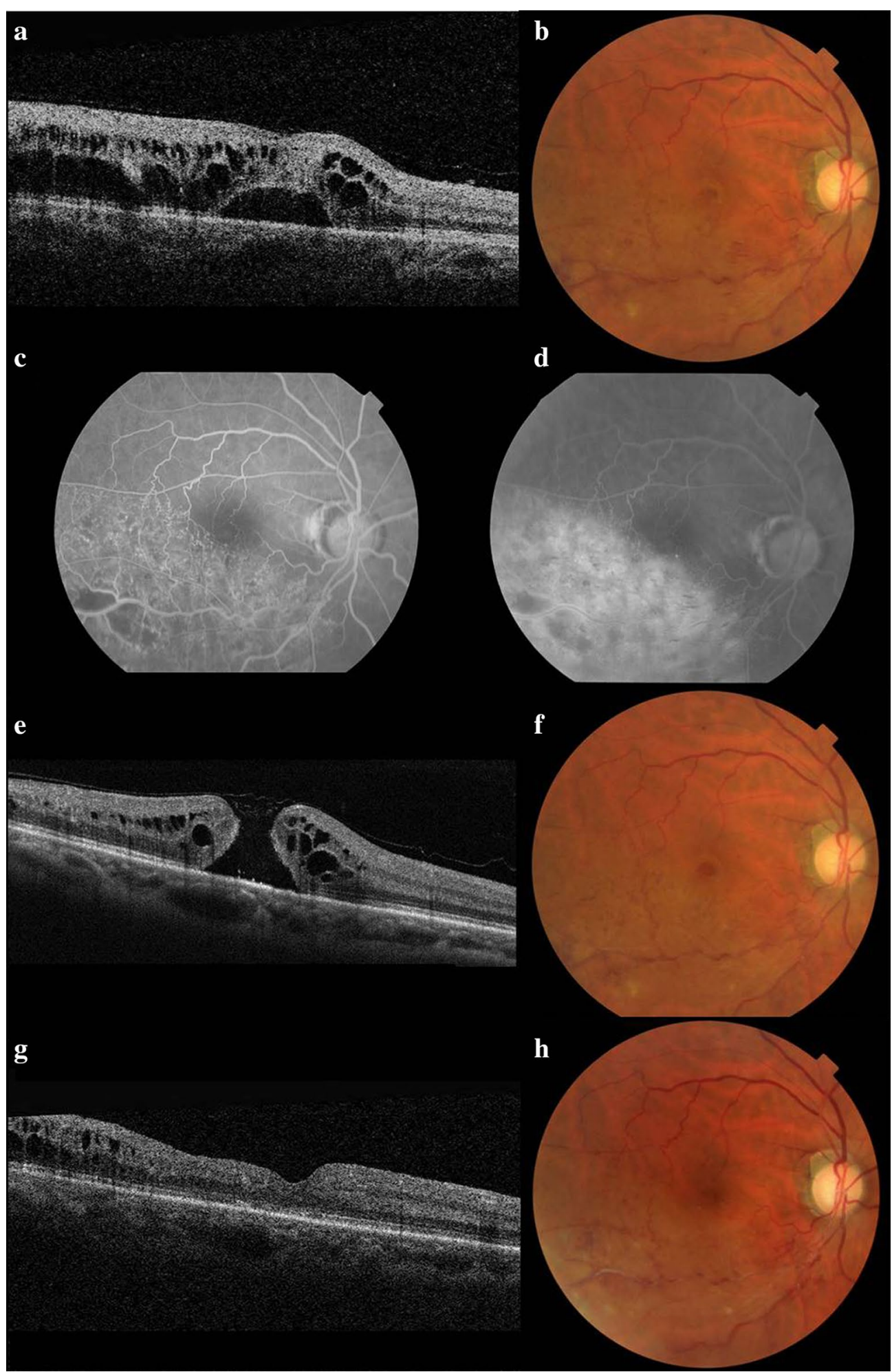

Fig. 1 B-scan optical coherence tomography (OCT) and color fundus photography before and after treatment. a, b Findings in the right eye before intravitreal administration of ranibizumab for chronic branch retinal vein occlusion. Serous retinal detachment and macular edema were located at the outer retina. $\mathbf{c}, \mathbf{d}$ Fluorescein angiography revealed a capillary nonperfusion area and dye leakage in the late phase. $\mathbf{e}$, $\mathbf{f}$ Nine days after injection of ranibizumab, OCT and color fundus photography showed formation of a full thickness macular hole and decreasing intraretinal edema. $\mathbf{g}, \mathbf{h}$ Five months after surgery, the macular hole was closed and macular edema decreased 
cortex was attached on the macula. After obtaining informed consent, the patient was administered $0.5 \mathrm{mg}$ ranibizumab intravitreally using a 32 gauge needle. Nine days after injection, BCVA in his right eye improved to $20 / 100$. OCT showed the formation of a full thickness $\mathrm{MH}$ and decreasing intraretinal edema (Fig. 1e). Twentytwo days after injection, BCVA further recovered to 20/50, but the $\mathrm{MH}$ was still open. The patient underwent 25 gauge pars plana vitrectomy, combined with cataract surgery and intraocular lens implantation. Internal limiting membrane peeling, photocoagulation to the nonperfusion area, and gas tamponade using $20 \%$ sulfur hexafluoride were successfully performed. One day after surgery, OCT confirmed successful closure of the $\mathrm{MH}$. Five months after surgery, BCVA recovered to 20/40 and CRT decreased to $272 \mu \mathrm{m}$ (Fig. 1g).

\section{Discussion}

There have been several reports of $\mathrm{MH}$ formation after intravitreal anti-VEGF therapy [7-12]. They included myopic choroidal neovascularization [7], age-related macular degeneration (AMD) [8-10], polypoidal choroidal vasculopathy [11], and hemicentral retinal vein occlusion [12]. However, to the best of our knowledge, this is a first report of $\mathrm{MH}$ formation after anti-VEGF therapy for BRVO.

The mechanism of $\mathrm{MH}$ formation after choroidal neovascularization $(\mathrm{CNV})$ treatment may have involved the rapid volume reduction of $\mathrm{CNV}$ after anti-VEGF therapy [7, 8]. However, Grigoropoulos et al. [10] described the cause of $\mathrm{MH}$ formation as a force not only to the retinal pigment epithelium (RPE), but also to the retinal surface. Querques et al. [9] reported increasing vitreous macular traction after ranibizumab injection, with formation of a stage $2 \mathrm{MH}$. In AMD treatment with anti-VEGF therapy, the responsible factors for $\mathrm{MH}$ formation were assumed to exist at the RPE, retinal surface, and vitreous [7].

Nagpal et al. reported $\mathrm{MH}$ formation after bevacizumab injection to a hemi-central retinal vein occlusion patient. In this patient, rapid posterior vitreous detachment (PVD) after injection was a possible causative factor for the development of the $\mathrm{MH}$ [12]. In our case, the PVD itself might not have been a causative factor for $\mathrm{MH}$ formation, because PVD was induced with active aspiration during surgery. However, as in former reports, there was a possibility of vitreous macular traction.

The expression of transforming growth factor (TGF)- $\beta 2$, which is known to cause fibrosis, was reported after anti-VEGF therapy $[13,14]$. In proliferative diabetic retinopathy, acceleration of pathologic fibrosis by antiVEGF therapy was also reported [15]. In our case, acute regression of macular edema and increased fibrosis might have triggered a mechanical force to the damaged retina, and might have been a possible cause of $\mathrm{MH}$ formation.

\section{Conclusions}

Anti-VEGF therapy is a powerful and standard modality for management of macular edema following BRVO. However, the possibility of infrequent complications like $\mathrm{MH}$ should be considered after intravitreal injection of ranibizumab.

\section{Consent}

Written informed consent was obtained from the patient for publication of this Case Report and any accompanying images. A copy of the written consent is available for review by the Editor-in-Chief of this journal.

\section{Abbreviations \\ RVO: retinal vein occlusion; BRVO: branch retinal vein occlusion; VEGF: vascular endothelial growth factor; $\mathrm{MH}$ : macular hole; BCVA: best-corrected visual acuity; OCT: optical coherence tomography; CRT: central retinal thickness; AMD: age-related macular degeneration; CNV: choroidal neovascularization; RPE: retinal pigment epithelium; PVD: posterior vitreous detachment; TGF: transforming growth factor.}

\section{Authors' contributions}

DM treated the patient, designed this project, and drafted the manuscript. RM participated in treatment for the patient and the collection of data and helped to draft the manuscript. TI, MM, HG participated in its conception and revising this manuscript. All authors read and approved the final manuscript.

\section{Author details}

${ }^{1}$ Tokyo Medical University, Ibaraki Medical Center, 3-20-1 Chuo, Ami-machi, Inashiki-gun, Ibaraki 300-0395, Japan. ${ }^{2}$ Tokyo Medical University, 6-7-1 Nishishinjuku, Shinjuku-ku, Tokyo 160-0023, Japan.

Acknowledgements

None.

\section{Compliance with ethical guidelines}

\section{Competing interests}

The authors declare that they have no competing interests.

Received: 1 April 2015 Accepted: 11 August 2015

Published online: 19 August 2015

\section{References}

1. The Branch Vein Occlusion Study Group. Argon laser photocoagulation for macular edema in branch vein occlusion. Am J Ophthalmol. 1984;98:271-82

2. Scott IU, Ip MS, VanVeldhuisen PC, Oden NL, Blodi BA, Fisher M, Chan CK, Gonzalez VH, Singerman LJ, Tolentino M, SCORE Study Research Group. A randomized trial comparing the efficacy and safety of intravitreal triamcinolone with standard care to treat vision loss associated with macular Edema secondary to branch retinal vein occlusion: the Standard Care vs Corticosteroid for Retinal Vein Occlusion (SCORE) study report 6. Arch Ophthalmol. 2009;127:1115-28.

3. Okunuki Y, Usui Y, Katai N, Kezuka T, Takeuchi M, Goto H, Wakabayashi Y. Relation of intraocular concentrations of inflammatory factors and improvement of macular edema after vitrectomy in branch retinal vein occlusion. Am J Ophthalmol. 2011;151:610-6. 
4. Campochiaro PA, Heier JS, Feiner L, Gray S, Saroj N, Rundle AC, Murahashi WY, Rubio RG, BRAVO Investigators. Ranibizumab for macular edema following branch retinal vein occlusion: six-month primary end point results of a phase III study. Ophthalmology. 2010;117:1102-12.

5. Ogura Y, Roider J, Korobelnik JF, Holz FG, Simader C, Schmidt-Erfurth U, Vitti R, Berliner AJ, Hiemeyer F, Stemper B, Zeitz O, Sandbrink R, GALILEO Study Group. Intravitreal aflibercept for macular edema secondary to central retinal vein occlusion: 18-month results of the phase 3 GALILEO study. Am J Ophthalmol. 2014;158:1032-8.

6. Rosenfeld PJ, Fung AE, Puliafito CA. Optical coherence tomography findings after an intravitreal injection of bevacizumab (avastin) for macular edema from central vein occlusion. Ophthalmic Surg Lasers Imaging. 2005;36:336-9.

7. Miura M, Iwasaki T, Goto H. Macular hole formation after intravitreal bevacizumab administration in a patient with myopic choroidal neovascularization. Retin Cases Brief Rep. 2011;5:149-52.

8. Moisseiev E, Goldstein M, Loewenstein A, Moisseiev J. Macular hole following intravitreal bevacizumab injection in choroidal neovascularization caused by age-related macular degeneration. Case Rep Ophthalmol. 2010;1:36-41.

9. Querques G, Souied EH, Soubrane G. Macular hole following intravitreal ranibizumab injection for choroidal neovascular membrane caused by age-related macular degeneration. Acta Ophthalmol. 2009;87:235-7.
10. Grigoropoulos V, Emfietzoglou J, Nikolaidis P, Theodossiadis G, Theodossiadis P. Full-thickness macular hole after intravitreal injection of ranibizumab in a patient with retinal pigment epithelium detachment and tear. Eur J Ophthalmol. 2010;20:469-72.

11. Cho JH, Park SE, Han JR, Kim HK, Nam WH. Macular hole after intravitreal ranibizumab injection for polypoidal choroidal vasculopathy. Clin Exp Optom. 2011;94:586-8.

12. Nagpal M, Mehta $V$, Nagpal K. Macular hole progression after intravitreal bevacizumab for hemicentral retinal vein occlusion. Case Rep Ophthalmol. 2011; doi:10.1155/2011/679751.

13. Forooghian F, Kertes PJ, Eng KT, Agrón E, Chew EY. Alterations in the intraocular cytokine milieu after intravitreal bevacizumab. Invest Ophthalmol Vis Sci. 2010;51:2388-92.

14. Nakao S, Ishikawa K, Yoshida S, Kohno R, Miyazaki M, Enaida H, Kono T, Ishibashi T. Altered vascular microenvironment by bevacizumab in diabetic fibrovascular membrane. Retina. 2013;33:957-63.

15. Arevalo JF, Maia M, Flynn HW Jr, Saravia M, Avery RL, Wu L, Eid Farah M, Pieramici DJ, Berrocal MH, Sanchez JG. Tractional retinal detachment following intravitreal bevacizumab (Avastin) in patients with severe proliferative diabetic retinopathy. $\mathrm{Br} J$ Ophthalmol. 2008;92:213-6.

\section{Submit your next manuscript to BioMed Central and take full advantage of:}

- Convenient online submission

- Thorough peer review

- No space constraints or color figure charges

- Immediate publication on acceptance

- Inclusion in PubMed, CAS, Scopus and Google Scholar

- Research which is freely available for redistribution

Submit your manuscript at

www.biomedcentral.com/submit

() BioMed Central 